\title{
AKTIVITAS RISIKO DAN STATUS STAIN EKSTRINSIK GIGI PADA MASYARAKAT RT 004 RW 001 KAMPUNG BALI TANAH ABANG
}

\author{
Ni Nyoman Kasihani ${ }^{1}$, Rahaju Budiarti ${ }^{2}$, Pudentiana RR RE ${ }^{3}$, Erwin ${ }^{4}$, Annida Fathiyah Mujahidah \\ 1,2,3,4,5 Jurusan Keperawatan Gigi, Politeknik Kesehatan Kemenkes Jakarta I, Indonesia
}

\begin{tabular}{|c|c|}
\hline Info Artikel & Abstrak \\
\hline $\begin{array}{l}\text { Genesis Naskah: } \\
\text { Submitted: } 3 \text { Maret } 2020 \\
\text { Revised: } 12 \text { Maret } 2020 \\
\text { Accapted: } 24 \text { Maret } 2020 \\
\text { Kata Kunci: } \\
\text { Aktivitas resiko, Merokok, } \\
\text { Konsumsi minuman } \\
\text { Berwarna, Stain Ekstrinsik }\end{array}$ & $\begin{array}{l}\text { Latar belakang: Stain adalah endapan berpigmen pada permukaan gigi, salah satu penyebabnya } \\
\text { adalah aktivitas pencetus resiko perlekatan warna seperti konsumsi minuman berwarna,dan me } \\
\text { rokok yang meninggalkan tar kecoklatan pada kehitaman pada gigi yang terjadi secara perlahan } \\
\text { selama periode waktu yang lama. Perubahan warna ini dapat menyebabkan masalah estetika yang } \\
\text { dapat memberikan dampak psikologis yang cukup besar, terutama jika itu terjadi pada gigi } \\
\text { anterior. Tujuan: penelitian ini adalah untuk mengetahui aktivitas resiko dan status stain } \\
\text { ekstrinsik gigi masyarakat di komunitas RT } 004 \mathrm{RW} 001 \text { di Kampung Bali Tanah Abang. Jenis } \\
\text { penelitian ini adalah penelitian deskriptif. besar Sampel sampel } 47 \text { orang yang diambil dengan } \\
\text { teknik purposive sampling. Metode Pengumpulan Data dengan wawancara dan pemeriksaan stain } \\
\text { pada gigi. Hasil penelitian menunjukkan bahwa sampel dengan kebiaasan merokok sebesar } 32 \% \text {, } \\
\text { sampel dengan kebiasaan konsumsi minuman berwarna sebesar } 96 \% \text {. dan kategori stain ekstrinsik } \\
\text { sampel umumnya pada kategori sedang sebesar } 62 \% \text {. }\end{array}$ \\
\hline
\end{tabular}

\section{RISK ACTIVITIES AND DENTAL EXTRINSIC STAIN STATUS OF COMMUNITIES RT 004 RW 001 KAMPUNG BALI TANAH ABANG}

\section{Keywords:}

Risk activities, smoking, consumption of colored drinks, extrinsic stain

\section{Abstract}

Background: Stain is pigmented deposits on the surface of the teeth, one of the causes is the activity of triggering the risk of adhesion of colors such as consumption of colored drinks, and smoking which leaves brownish tar on blackish teeth which slowly occurs over a long period of time. This discoloration can cause aesthetic problems which can have a considerable psychological impact, especially if it occurs in the anterior teeth. Objective: this study was to determine the risk activity and status of extrinsic staining of community teeth in the RT 004 RW 001 community in Kampung Bali Tanah Abang. This type of research is descriptive research. Sample size 47 people were taken by purposive sampling technique. Data collection methods with interviews and dental stain examination. The results showed that the sample with the habit of smoking was 32\%, the sample with the habit of consuming colored drinks was 96\%. and the sample extrinsic stain category is generally in the moderate category at $62 \%$.

\footnotetext{
Korespondensi Penulis:

Nyoman Kasihani

Jl. Wijaya Kusuma No. 47-48 Cilandak Jakarta Selatan

Email :nyoman.kasihani@gmail.com
} 


\section{Pendahuluan}

Kesehatan Gigi dan Mulut seringkali menjadi prioritas yang kesekian bagi sebagian orang. Padahal seperti kita ketahui, gigi dan mulut merupakan pintu gerbang masuknya kuman dan bakteri sehingga dapat menganggu kesehatan organ tubuh lainnya

kesehatan gigi dan mulut adalah keadaan sehat dari jaringan keras dan jaringan lunak gigi serta unsurunsur yang berhubungan dalam rongga mulut, yang memungkinkan individu makan, berbicara dan berinteraksi sosial tanpa disfungsi, gangguan estetik, dan ketidaknyamanan karena adanya penyakit, penyimpangan oklusi dan kehilangan gigi sehingga mampu hidup produktif secara sosial dan ekonomi (Kemenkes RI, 2018)

Berdasarkan laporan dari hasil data Riset Kesehatan Dasar (Riskesdas) Nasional tahun 2018, mencatat rendahnya proporsi perilaku menyikat gigi dengan benar yaitu sebesar 2,8\% . Dari data tersebut, kesehatan gigi dan mulut masih sangat perlu mendapat perhatian (Kemenkes RI, 2018)

Pada umumnya penilaian orang lain pertama kali adalah dari penampilannya. Memiliki senyum indah dengan gigi putih cemerlang adalah idaman semua orang. Dengan gigi yang sehat dan putih sehingga membuat seseorang merasa lebih muda dan percaya diri (Hermawan, 2010).

Perubahan warna gigi dapat menimbulkan persoalan estetika yang dapat memberikan dampak psikologi yang cukup besar, terutama apabila terjadi pada gigi depan. Perubahan warna gigi dapat terjadi seiring dengan bertambahnya umur, karena dentin dapat lebih tebal. Akibat deposisi dentin sekunder dan dentin reparatik, sehingga menghasilkan perubahan warna pada gigi (Hermawan, 2010)

Stain atau noda berwarna pada gigi dapat disebabkan oleh minuman berwarna seperti kopi, teh. Warna stain yang terlihat pada gigi berasal dari komponen polyphenol, yang memberikan warna pada minuman, ditambah dengan oral hygiene yang buruk dapat menyebabkan pembentukan plak dan kalkulus yang mempengaruhi warna pada gigi. Selain kopi dah teh pewarnaan pada gigi juga disebabkan oleh rokok.

Stain merupakan pewarnaan pada permukaan gigi. Pewarnaan tersebut terdapat pada permukaan luar gigi (ekstrinsik) maupun yang berasal dari dalam gigi (intrinsik). Gangguan yang diakibatkan oleh stain terutama adalah masalah estetik

(C) Jurusan Keperawatan Gigi Poltekkes Kemenkes Jakarta I

Jl. Wijaya Kusuma No. 47-48 Cilandak Jakarta Selatan, Indonesia

email: jdht@poltekkesjakarta1.ac.id
Berdasarkan hasil Riset Kesehatan Dasar (Riskesdas) tahun 2018 tentang rendahnya proporsi menyikat gigi dengan baik dan benar, dan survei awal yang dilakukan masyarakat RT 004 RW 001 Kelurahan Kampung Bali Tanah Abang ditemukan banyak masyarakat yang memiliki pewarnaan berwarna kecoklatan pada gigi, dan berdasarkan informasi masyarakat tersebut memiliki kebiasaan minum minuman berwarna seperti kopi, teh dan merokok setiap hari.

\section{Metode}

Jenis penelitian ini adalah penelitian deskriptif. Penelitian ini di lakukan di RT 004 RW 001 Kelurahan Kampung Bali pada Maret-Juni 2019. Populasi pada penelitian ini adalah seluruh masyarakat yang berusia 26 tahun ke atas yang berjumlah 73 orang. Besar sampel penelitian ini sebanyak 47 orang diambil dengan teknik purposive sampling. Pengumpulan data dilakukan dengan wawancara aktivifitas resiko pewarnaan esktrinsik gigi yang terbagi atas aktivitas merokok dan konsumni minuman berwarna dan pemeriksaan stain ekstrinsik dengan indeks stain menurut Lobene. Analisis data dilakukan secara deskriptif.

\section{Hasil Penelitian}

Hasil penelitian disajikan sebagai berikut:

Gambar 1. Distribusi frekuensi status merokok

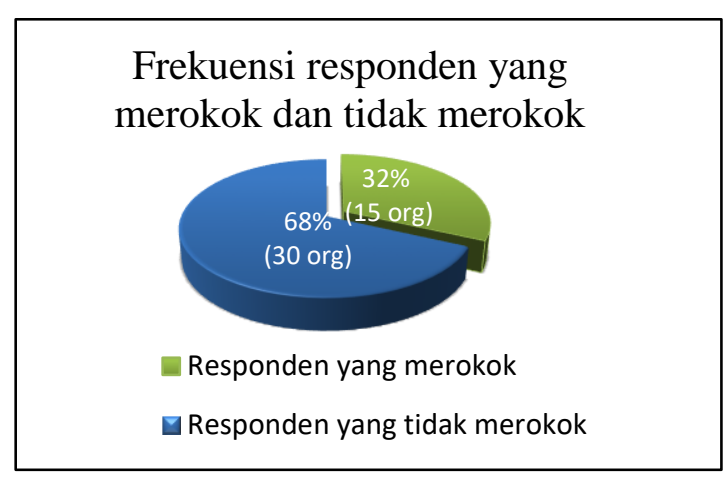

Berdasarkan gambar 1 menunjukkan sebagian besar responden diketahui tidak mempunyai kebiasaan merokok yaitu sebesar 68\%. Data penelitian juga menunjukkan pada kelompok perokok mayoritas perokok tersebut adalah laki-laki. 
Gambar 2. Distribusi frekuensi merokok

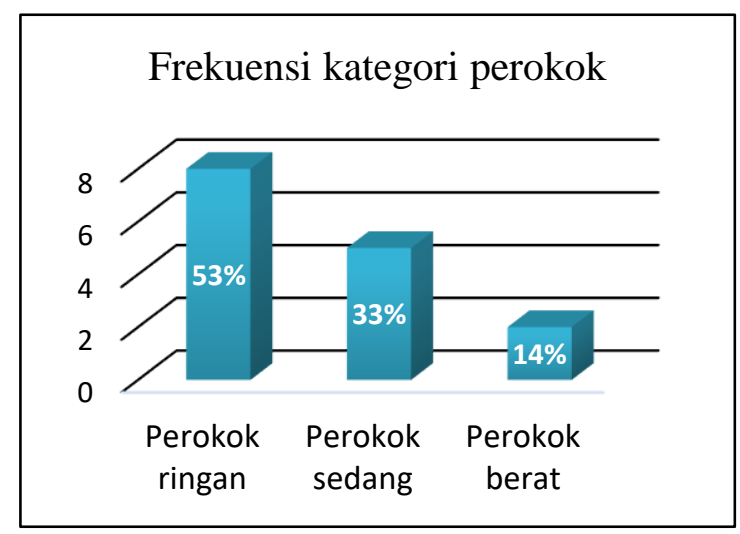

Berdasarkan gambar 2 menunjukkan dari 15 orang responden perokok diketahui mayoritas adalah perokok ringan yaitu sebesar 53\% (8 orang).

Gambar 3. Distribusi frekuensi kebiasaan konsumsi minuman berwarna

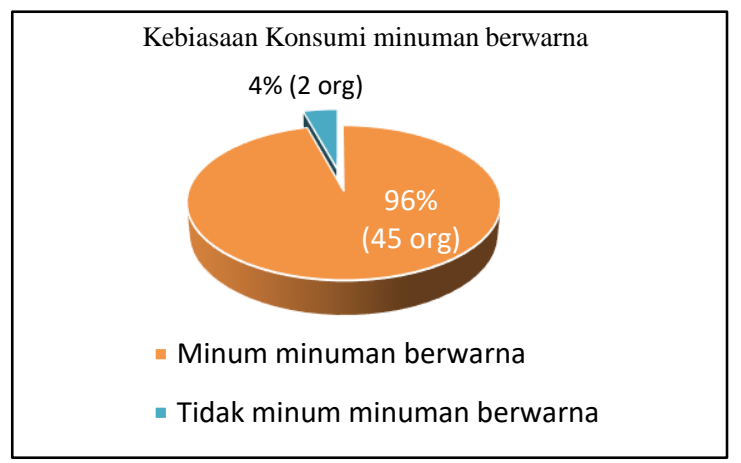

Berdasarkan gambar 3 menunjukkan sebagian besar responden diketahui mempunyai kebiasaan konsumsi minuman berwarna yaitu sebesar 96\% (45 orang).

Gambar 4. Distribusi Frekuensi Kebiasaan Konsumsi Minuman Berwarna

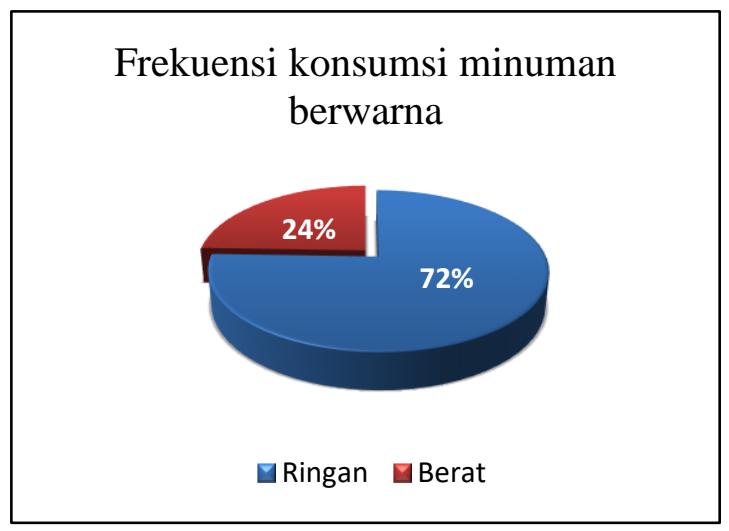

(C) Jurusan Keperawatan Gigi Poltekkes Kemenkes Jakarta I J1. Wijaya Kusuma No. 47-48 Cilandak Jakarta Selatan, Indonesia email: jdht@poltekkesjakarta1.ac.id
Berdasarkan gambar 4 menunjukkan dari 45 orang responden dengan kebiasaan konsumi minuman berwarna diketahui mayoritas dengan frekuensi ringan yaitu sebesar $72 \%$ (32 orang).

Tabel 5. Gambaran Stain Ekstrinsik

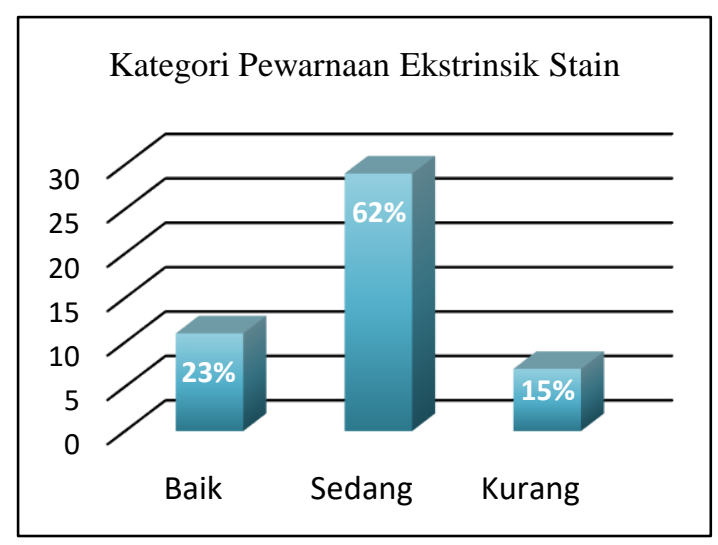

Berdasarkan gambar 5 menunjukkan dari 47 sampel yang diperiksa sebagian besar mempunyai stain ekstrinsik kategori sedang yaitu 62\% (29 orang).

\section{Pembahasan}

Data tabel 1 dan 2 diketahui sebagian besar responden yang merokok berjenis kelamin laki-laki, diketahui juga umumnya frekwensi merokok kelompok tersebut pada kategori ringan. Hasil tersebut sejakan dengan hasil Riset Kesehatan Dasar tahun 2018 menunjukkan konsumsi perokok terbanyak dari seluruh provinsi di Indonesia jika ditinjau dari jenis kelamin dengan persentase $62 \%$, laki-laki lebih banyak yang merokok dari pada perempuan (Kemenkes RI, 2018)

Menurut Brighim (1991) perilaku merokok bagi laki-laki merupakan perilaku simbolisasi yang disebabkan oleh faktor lingkungan dan harga diri, tekanan dalam bentuk ejekan ini membuat keberhargaan tentang diri seorang remaja mulai menurun dan kondisi ini sangat mujarab untuk membuat remaja segera mencoba merokok pada akhirnya menjadi perokok pemula dan lama kelamaan menjadi pecandu rokok.

Dengan demikian penulis berpendapat terbentuknya kebiasaan merokok yang umumnya ditemui pada kelompok laki-laki dapat dimulai dari masa remaja, yang terinisiasi oleh pengaruh pergaulan dalam komunitasnya. Pengulangan yang terus menerus dilakukan akan menjadikan perilaku tersebut menetap dan menjadi kebiasaan yang dianggap wajar seiring pertambahan usia dimasa dewasa. 
Data tabel 3 dan 4 diketahui sebagian besar responden dengan memiliki kerbiasaan konsumsi minuman berwarna, lebih spesifik hasil riset ini menunjukkan jenis minuman berwarna yang umumnya menjadi kebiasaan responden adalah teh dan kopi, diketahui juga umumnya frekwensi kebiasaan tersebut pada kategori ringan,. Hasil penelitian ini serupa dengan penelitian Febriana Ira Dewi, dkk (2019) terkait konsumsi minuman kafein mahasiswa TBP-IPB, hasil menunjukkan responden yang mengkonsumsi teh pada kelompok laki-laki sebesar 76,1\% dan pada kelompok perempuan sebesar $72,2 \%$.

Penulis berpendapat kebiasaan konsumsi minuman berwarna oleh sampel dilakukan karena telah menjadi kebiasaan rutin yang setiap hari yang dilakukan. Kebiasaan tersebut umumnya terjadwal secara teratur diwaktu tertentu atau melakukan aktivitas tertentu.. Sebagai contoh, pada kultur masyarakat kita sangat sering dijumpai kebiasaan konsumsi teh atau kopi untuk dikonsumsi pada pagi, sore atau malam hari, saat menyambut tamu, menggelar pertemuan, saat bekerja dikantor dan aktivitas lainnya. Konsumsi minuman tersebut secara umum dianggap simbol penghomatan, mampu menjaga fokus dan mendukung produktivitas aktivitasnya. Sebagaimana pendapat Santrock (2003) kopi dan teh memiliki kandungan kafein yang dapat mencegah kantuk. kafein merupakan salah satu stimulan yang paling luas penggunaannya, termasuk dikalangan remaja.

Remaja cepat sekali terpengaruh oleh keadaan lingkungan terutama dalam pemilihan jenis makanan atau minuman. Kebiasaan konsumsi dapat membentuk suatu pola sikap yang dapat terjadi berulang-ulang dalam mengonsumsi pangan tertentu. Remaja cenderung mempunyai kebiasaan yang kurang baik yaitu lebih menyukai minuman ringan, teh, dan kopi dengan frekuensi lebih sering (Hurlock, 1996, dalam Puri, 2007)

Data tabel 5 menunjukkan mayoritas sampel yang diperiksa status stain ekstrinsiknya pada kategori sedang. Hasil ini sejalan dengan hasil penelitian Reca \& Ainun (2019) yang melakukan pemeriksaan stain gigi pada masyarakat di Desa Peuniti Kota Banda Aceh dan ditemukan kasus stain sebesar $63 \%$.

Penulis berpendapat stain atau pewarnaan pada gigi sangat mungkin ditemukan pada setiap orang, selain karena faktor intrinsik, paparan faktor ekstrinsik yang terus-menerus turut memberi pengaruh terjadinya kasus tersebut. Tanpa upaya pembersihan yang baik, gigi akan sangat rentan terjadi pewarnaan ekstrinsik berupa menempel dan menumpuknya zat sisa bahan berwarna tertentu karena dalam jangka waktu lama berkontak terus-menerus dengan permukaan email gigi. Kerentanan tersebut diprediksi karena terjadinya reaksi kimia antara bahan permukaan email dengan bahan makanan/minuman tertentu. Sebagaimana pendapat Menurut Craig \& Supeene (1999) pelikel yang melapisi email diketahui mempunyai muatan negatif yang memungkinkan adhesi selektif terhadap ion ion positif dengan permukaan gigi. Hal tersebut dipercaya menjadi peran penting dalam deposisi stain padapermukaan gigi. Ion-ion dari makanan dan minuman yang mengandung tannin dan juga kromogen seperti tembaga, nikel dan besi melekat dengan muatan negatif pada pelikel shingga menyebabkan diskolorisasi gigi

\section{Kesimpulan dan Saran}

Berdasarkan hasil penelitian, dapat disimpulkan bahwa:

1. Masyarakat RT 004 RW 001 Kelurahan Kampung Bali Tanah Abang dengan kebiasaan merokok sebesar $32 \%$, dengan sebagian besar pada frekuesi ringan

2. Masyarakat RT 004 RW 001 Kelurahan Kampung Bali Tanah Abang yang memiliki kebiasaan konsumsi minuman berwarna sebesar $96 \%$ dengan sebagian besar pada frekwensi ringan

3. Stain ekstrinsik masyarakat RT 004 RW 001 Kelurahan Kampung Bali Tanah Abang mayoritas ditemukan pada kategori sedang sebesar $62 \%$.

Berdasarkan simpulan penelitian dapat disarankan sebagai berikut:

1. Disarankan terhadap sasaran dengan kebiasaan merokok untuk menghentikan kebiasaan tersebut.

2. Disarankan terhadap sasaran dengan kebiasaan konsumsi minuman berwarna untuk mengatur pola konsumsinya secara baik dan tidak berlebih-lebihan.

3. Disarankan terhadap sasaran dengan kasus stain ekstrinsik agar menerapkan pola pemeliharaan kesehatan gigi yang baik dan pembersihan stain dengan berkunjung melakukan perawatan gigi dan mulut pada petugas kesehatan gigi. 


\section{Daftar Pustaka}

Brighim, J. . (1991). Social Psychology. Edisi Kedua. New York: Harper Colling Publisher Inc.

Craig, BJ Supeene, L. (1999). Tooth Whitening: Efficacy, Effects and Biologic Safety. Probe Scientific Journal, 33(6), 169-174.

Dewi, Febriana Ira, D. (2019). Persepsi Terhadap Konsumsi Kopi Dan Teh Mahasiswa Tpb-Ipb. 4(1), 21-28.

Hermawan, R. (2010). Menyehatkan Daerah Mulut. Yogyakarta: Buku Biru.

Kemenkes RI. (2018). Hasil Utama Riset Kesehatan Dasar Tahun 2018. Kementrian Kesehatan Republik Indonesia. https://doi.org/1 Desember 2013
Puri, D. (2007). Faktor-faktor yang berhubungan dengan status anemia mahasiswi peserta program pemberian makan tambahan di IPB, Bogor. IPB.

Reca, R., \& Mardiah, A. (2019). Hubungan Pengetahuan Dan Sikap Masyarakat Dengan Pewarnaan Gigi (Stain) Di Desa Peuniti Kota Banda Aceh. Jurnal Bahana Kesehatan Masyarakat (Bahana of Journal Public Health), 3(1), 15-19.

Sandy, L. P. A., Kemenkes, R., \& Riskesdas, K. (2018). Permenkes 89 tahun 2015 tentang Upaya Kesehatan Gigi dan Mulut. Jurnal Teknosains, 44(8), 53.

Santrock. (2003). Perkembangan Remaja. (6th ed.). Jakarta: Erlangga. 